\title{
Cholinesterase inhibitors in Alzheimer's disease and Lewy body spectrum disorders: The emerging pharmacogenetic story
}

\author{
Benjamin Lam, ${ }^{1,2}$ Elizabeth Hollingdrake, ' James L. Kennedy, ${ }^{3}$ Sandra E. Black ${ }^{1,2}$ and Mario Masellis $1,2,3^{*}$ \\ 'L.C. Campbell Cognitive Neurology Research Unit, Sunnybrook Research Institute, Sunnybrook Health Sciences Centre, \\ University of Toronto, Toronto, Canada \\ ${ }^{2}$ Department of Medicine, Division of Neurology, University of Toronto, Toronto, Canada \\ ${ }^{3}$ Neurogenetics Section, Centre for Addiction and Mental Health, Department of Psychiatry, University of Toronto, Toronto, Canada \\ *Correspondence to: Tel: +1 416480 4661; Fax: +1 416480 5753; E-mail: Mario.Masellis@sunnybrook.ca
}

Date received (in revised form): 16th June 2009

\begin{abstract}
This review provides an update on the current state of pharmacogenetic research in the treatment of Alzheimer's disease (AD) and Lewy body disease (LBD) as it pertains to the use of cholinesterase inhibitors (ChEl). AD and LBD are first reviewed from clinical and pathophysiological perspectives. This is followed by a discussion of ChEls used in the symptomatic treatment of these conditions, focusing on their unique and overlapping pharmacokinetic and pharmacodynamic profiles, which can be used to identify candidate genes for pharmacogenetics studies. The literature published to date is then reviewed and limitations are discussed. This is followed by a discussion of potential endophenotypes which may help to refine future pharmacogenetic studies of response and adverse effects to ChEls.
\end{abstract}

Keywords: Alzheimer's disease, cholinesterase inhibitors, endophenotype, Lewy body disease, neuroimaging, pharmacogenetics

\section{Introduction}

The neurodegenerative dementias represent a major threat to the health and welfare of today's ageing population. Of them, Alzheimer's disease (AD), with or without cerebrovascular disease, is the most common, accounting for 50-80 per cent of cases. ${ }^{1}$ Lewy body disease (LBD) follows, making up at least another 20 per cent of cases. ${ }^{2,3}$ Together, the two inflict significant human suffering and mortality, with associated economic costs approaching 140 billion US\$ for AD alone. ${ }^{4}$ This problem will only worsen over time. The prevalence of AD doubles every five years after the age of 60 , and estimates now place its prevalence in the extreme elderly at $30-50$ per cent. ${ }^{5}$ In early 2000 , it was estimated that the number of people suffering from dementia worldwide ranged between 24 and 25 million, and this is predicted to increase to $60-114$ million by $2050 .^{6-9}$

Symptomatic treatment for AD and LBD includes cholinesterase inhibitors (ChEIs), which increase synaptic levels of the neurotransmitter, acetylcholine. Several randomised, controlled trials (RCTs) of ChEIs in $\mathrm{AD}$ have demonstrated variable rates of improvement, ranging between 18 and 48 per cent. ${ }^{10}$ Their beneficial effects, demonstrated through 
meta-analyses, are modest in terms of cognitive and global measures of response. ${ }^{10,11}$ Furthermore, adverse effects associated with ChEIs are not benign and may limit their use in individual patients. With an 8 per cent occurrence rate compared with placebo. ${ }^{10}$ These drugs are also costly, and, given their modest benefit and potential for adverse effects, the cost-effectiveness of ChEIs has been brought into question. ${ }^{11}$

Significant effort is underway to develop diseasemodifying treatments for these conditions, and, despite many promising new therapies in the pipeline, ${ }^{12}$ several of these have failed to show any significant benefit and/or are plagued by tolerability issues. ${ }^{13}$ Therefore, it is likely that for the next few years, ChEIs will remain the mainstay for the treatment of $\mathrm{AD}$ and LBD, or, more likely, they will be one important component of a medication 'cocktail' used to treat these conditions. As such, optimisation of response and minimisation of adverse effects in individual patients is a priority. Understanding the pharmacogenetics - that is, the hereditary basis of person-to-person variability in the response to and adverse effects of ChEIs - may help better to achieve this goal. The clinical application of pharmacogenetics may allow clinicians to eventually target the 'right' ChEI to the 'right' patient, thereby circumventing the current 'trial and error' approach to prescribing, with the significant potential of improving their cost-effectiveness.

\section{The "cholinesterase inhibitor-responsive dementias': Alzheimer's disease and Lewy body disease}

At its core, $\mathrm{AD}$ involves a progressive impairment of episodic memory, ${ }^{14}$ with deficits in other cognitive domains, commonly visuospatial and executive functions, the latter being defined by complex, goaldirected behaviours including initiating, planning, organising, sequencing and abstracting. The declining ability to manage instrumental and self-care activities of daily living account for much of the disease burden. ${ }^{4}$ These core features are incorporated into a new set of research diagnostic criteria, which recommend the use of genetic, cerebrospinal fluid (CSF) and imaging biomarkers to improve on the accuracy of diagnosis of AD. ${ }^{15}$ While these clinical criteria permit the diagnosis of probable disease, definitive confirmation comes from the postmortem identification of extracellular amyloid plaques consisting of dystrophic neurites surrounding a core of beta-amyloid $(A \beta)$ protein, and intracellular neurofibrillary tangles formed from the hyperphosphorylated microtubule-associated protein Tau. ${ }^{16}$

Dementia with Lewy bodies (DLB) and Parkinson's disease with dementia (PDD) are neurodegenerative disorders characterised by the pathological hallmark of intraneuronal Lewy bodies and neurites. These intraneuronal inclusions contain an aggregated, insoluble form of $\alpha$-synuclein-a presynaptic protein implicated in synaptic vesicle production. $^{2}$ As such, they are classified as synucleinopathies representing part of a similar disease spectrum, called diffuse Lewy body disease (LBD).

Like AD, DLB presents with forgetfulness, but the predominant cognitive profile includes an inattentive-dysexecutive syndrome with profound visuospatial disturbance. ${ }^{17-19}$ DLB is also characterised by marked fluctuations in cognition and alertness, which can at times be severe enough to be mistaken for complex partial seizures. Sufferers of DLB are also plagued by hallucinations (usually visual), and atypical parkinsonism. In fact, marked fluctuations cognitive, visual hallucinations and spontaneous parkinsonism comprise the core clinical features of the disease, with several supportive and suggestive features also contributing. ${ }^{19}$

Parkinson's disease, a related synucleinopathy, presents with early parkinsonism, including tremor, rigidity and bradykinesia, which respond well to dopaminergic therapy. ${ }^{20}$ When someone with a diagnosis of Parkinson's Disease develops cognitive and neuropsychiatric decline similar to that seen in DLB more than one year after the onset of the motor symptoms, the disease evolution is considered to be PDD. ${ }^{2,21}$ At later stages, DLB and PDD are indistinguishable from each other on clinical, neurochemical and pathological grounds. ${ }^{17,22,23}$ LBD will be used to refer to DLB and PDD in this paper. As with AD, the changes wrought by LBD result in marked 
functional decline, and the prominent behavioural symptoms often rapidly lead to institutionalisation. More often than not, LBD co-exists with Alzheimer's-type pathology in the brain, further demonstrating the overlap between these two devastating neurodegenerative disorders. ${ }^{24}$

\section{Therapy targeting the cholinergic system: Cholinesterase inhibitors}

Both AD and LBD share an observed failure of the ascending cholinergic system of the brain.

There is both marked neuronal dropout and reduced synaptic densities in projections from cholinergic neurones located in the substantia innominata of the basal forebrain, including the nucleus basalis of Meynert, which projects to all cortical areas, and the septal nuclei, projecting to the hippocampus. ${ }^{25-28}$ The cholinergic deficits are more profound in LBD than in $\mathrm{AD}^{28}$ and many studies have suggested a more robust response to ChEIs in LBD than in AD. This is hypothesised to be on the basis that there is less actual cell loss and preservation of post-synaptic cholinergic receptors in $\mathrm{LBD}^{23,29}$ The mainstay of treatment for the cognitive symptoms of $\mathrm{AD}$ and LBD is aimed at addressing the limbic and cortical cholinergic deficit common to both diseases. At present, there are three agents commonly used: donepezil, rivastigmine and galantamine.

A fourth ChEI, tacrine, has fallen out of favour because of liver enzyme elevations observed in up to 40-50 per cent of patients. ${ }^{30,31}$ A fifth, noncholinergic agent, memantine, works through the alternative mechanism of N-methyl D aspartate (NMDA) receptor antagonism, whereby glutamatemediated excitotoxicity is reduced. ${ }^{32}$ While this approach has some proven efficacy in moderate to severe $\mathrm{AD}$, a review of this agent and its pharmacogenetic aspects is beyond the scope of this paper.

\section{Pharmacology of cholinesterase inhibitors: Identification of candidate genes for pharmacogenetic studies}

In order for a drug to exert its biological effect, it must first accumulate in the tissue(s) where its pharmacological 'target(s)' is/are located. Pharmacokinetics (PK) explains how a drug achieves this by examining the drug concentration versus time relationships in an organism through mathematical modelling of its absorption from site of administration, its distribution in tissues throughout the body, its metabolism by various enzyme systems and its excretion from the body (ADME framework). ${ }^{33,34}$ Once a drug is concentrated in the tissue, it interacts with the 'target(s)' through which the final biological effects are elicited (pharmacodynamic interaction). Specifically, pharmacodynamics (PD) describes the drug concentration versus effect relationships in an organism. ${ }^{33,34}$ The targets may include a variety of proteins, such as enzymes, receptors, transporters, ion channels and second messengers, among others. Alternatively, a drug may directly or indirectly interact with DNA or RNA to produce its biological effects. The PK-PD paradigm will now be applied to ChEIs to identify candidate genes for pharmacogenetic studies.

\section{Pharmacokinetics of cholinesterase inhibitors}

Drug metabolism is one of the pivotal factors contributing to variability in the PK of ChEIs and other drugs. ${ }^{35}$ Donepezil and galantamine are metabolised in the liver by cytochrome P450 2D6 (CYP2D6) and CYP3A4 enzymes. ${ }^{36,37}$ They undergo extensive first-pass metabolism. Of the major metabolites of donepezil, the CYP2D6 product has equal pharmacological activity to the parent compound, while the CYP3A4 metabolite is inactive. Therefore, variation in CYP3A4 metabolism should play a significant role in the variable clinical effects of donepezil. The main CYP2D6 metabolite of galantamine is three times more potent than the parent compound as a ChEI and can account for up to 20 per cent of an orally administered dose. Thus, variation in CYP2D6 metabolism might contribute to variability in the clinical effect of this drug. Galantamine clearance was found to be reduced by 25 per cent in poor metabolisers of CYP2D6. ${ }^{36}$ Redundant metabolic pathways, however, including CYP3A4 metabolism, make CYP2D6 polymorphism unlikely to 
be of consequence in determining its pharmacodynamic profile. ${ }^{38}$ Unlike donepezil and galantamine, rivastigmine does not undergo significant hepatic microsomal oxidation by CYP enzymes. Instead, it is rapidly and extensively metabolised in the serum and at its site of action by cholinesterases. ${ }^{36,37}$ Following metabolism, it is quickly eliminated by the kidneys.

\section{Pharmacodynamics of cholinesterase inhibitors}

ChEIs bind to and inhibit acetylcholinesterase (protein abbreviation: AChE; gene name: ACHE) and butyrylcholinesterase (protein abbreviation: BChE; gene name: $B C H E)$, which are enzymes responsible for the hydrolysis of acetylcholine at the synapse. ${ }^{39,40}$ This inhibition increases the amount of synaptic acetylcholine available for nicotinic and muscarinic cholinergic receptor stimulation both centrally and peripherally. Central inhibition is necessary for their cognitive enhancing effects, while peripheral blockade is thought to be responsible for their common dose-dependent side effects. $\mathrm{AChE}$ and $\mathrm{BChE}$ are similar from a molecular perspective and have been well characterised in terms of their structure-activity relationships. The proteins form a central gorge area, within which lie two types of molecular binding sites, an anionic and an esteratic site. ${ }^{39}$ The central esteratic site is where the hydrolysis of acetylcholine and related molecules takes place, while the anionic site binds to the cationic quaternary nitrogen of choline. ${ }^{39,40}$ Similar sites reside peripherally in these enzymes and are responsible for docking and facilitating the transport of acetylcholine to the central sites. Theoretically, genetic polymorphisms causing amino acid changes at either the gorge or peripheral sites could lead to variation in synaptic acetylcholine levels.

Donepezil and galantamine are short-acting competitive inhibitors, which bind reversibly to cholinesterases. ${ }^{36}$ By contrast, rivastigmine is actively metabolised by cholinesterases, thus making it an intermediate-acting or 'pseudo-irreversible' inhibitor. ${ }^{36}$ Although all three drugs have an affinity for both $\mathrm{AChE}$ and $\mathrm{BChE}$, donepezil and galantamine selectively inhibit AChE to a greater extent than $\mathrm{BChE}$, whereas rivastigmine has equal affinity for both. ${ }^{36}$ Rivastigmine, through this additional blockade of BChE, is thought to be of particular benefit in LBD. ${ }^{29,41,42}$ The ChEIs indirectly increase acetylcholine neurotransmission by facilitating stimulation at muscarinic and nicotinic receptors. Additionally, galantamine modulates nicotinic receptorsparticularly those comprising $\alpha 7$ subunits-by binding to an allosteric site and further enhancing cholinergic neurotransmission. ${ }^{43}$ As a consequence, we can anticipate that genetic polymorphism within $A C H E$ will be qualitatively more important for the pharmacogenetics of donepezil and galantamine. Polymorphisms within both $A C H E$ and $B C H E$ should theoretically have equal importance to the pharmacogenetics of rivastigmine. Polymorphisms within the gene encoding the $\alpha 7$-nicotinic receptor (CHRNA7) may have increased importance in the pharmacogenetics of galantamine.

\section{Variability in treatment response and side effects to cholinesterase inhibitors: Pharmacogenetics and pharmacogenomics}

Clinically, there is significant variability in the response and side effects to ChEIs in AD and LBD, ranging from no response or gradual worsening, to a slowed rate of symptomatic decline, to improvement in cognition and behaviour, although this is time limited. ${ }^{37,44-46}$ Both genetic and environmental factors probably play a role in the variability of drug responses, which display complex, non-Mendelian patterns of inheritance. ${ }^{47-49}$ Pharmacogenetics may help to shed light on this variability in the treatment response and side effects to ChEIs.

Interestingly, one of the initial observations which originated the field of pharmacogenetics has direct relevance to ChEIs. This was the discovery of atypical plasma cholinesterase or pseudocholinesterase. ${ }^{50}$ In the 1950 s, Professor Werner Kalow, one of the founding fathers of pharmacogenetics, studied plasma cholinesterase activity in two patients with schizophrenia who had prolonged 
apnoea in response to the paralytic agent, succinylcholine. He found that their plasma cholinesterase activity was low and postulated that this was due to a genetic change in the enzyme which gave rise to a low affinity for the drug. By studying plasma cholinesterase activity in family members of these patients, he demonstrated that the patients had the lowest enzyme activity, while their parents had intermediate activity and controls had normal activity. He postulated that the patients each had two abnormal copies of the gene encoding plasma cholinesterase, that their parents had one normal and one abnormal copy, and that controls had two normal copies, consistent with a Mendelian pattern of co-dominant inheritance. ${ }^{51}$ Another contemporary group demonstrated similar findings. ${ }^{52}$ Later, the gene encoding plasma cholinesterase was recognised to be BCHE, and currently more than 40 mutations have been discovered, several of which alter protein function or expression; ${ }^{39}$ the two most common mutations altering enzyme function are the K-variant, which was named after Professor Kalow, and the atypical variant.

Since these initial observations, the field of pharmacogenetics has vastly expanded and molecular genetic techniques are being widely applied to identify genetic factors in the variability of drug responses and side effects. To date, the majority of pharmacogenetic studies of ChEIs in AD and LBD have employed the candidate gene association strategy. This entails collecting large number of samples from unrelated individuals with either AD or LBD who are being initiated on ChEI therapy. Data can be collected either prospectively or retrospectively, and clinical response is measured using psychometric scales such as the Alzheimer's Disease Assessment Scale (ADAS)-Cognitive (Cog) subscale. ${ }^{53}$ Behavioural, functional and quality of life measures are also commonly used. Clinical response status over time can be defined based on an appropriate cut-off score or, alternatively, mean change in scores over time can be used as a quantitative measure. Adverse effects can also be measured in terms of frequency, or quantified using a rating scale of severity. Candidate genes with informative polymorphisms are then selected and genotyped in the study population. These polymorphisms are statistically associated with the response or adverse effect phenotype to determine their ability to predict them.

The decision to study a particular candidate gene should be based on the degree to which its protein product interacts with the drug. It is a requirement of the genetic association approach that there is prior evidence suggesting a role for the candidate gene in the phenotype of interest. ${ }^{54}$ As previously proposed, 'direct' candidate gene polymorphisms have a higher a priori likelihood of being associated with the drug response phenotype and will account for a larger proportion of the variance in response. ${ }^{49}$ As an example, ACHE would be considered a 'direct' candidate gene-since the enzyme, AChE, is directly inhibited by all ChEIs. Other 'direct' candidate genes include BCHE, the protein product of which is strongly inhibited by rivastigmine; CHRNA7, the protein product of which is modulated by galantamine; and CYP2D6 and CYP3A4, which code for enzymes involved in the metabolism of donepezil and galantamine. This contrasts with 'indirect' candidate genes which may be linked either upstream or downstream of the final common pathway of drug response. ${ }^{49}$ Apolipoprotein E (gene name: $A P O E$ ), discussed in the following section, represents an 'indirect' candidate gene, since there is no known direct interaction between its protein product and ChEIs. Polymorphisms within the candidate genes which have functional consequences or which alter protein levels should preferably be genotyped, rather than those which are silent or nonfunctional, and by studying the former, one can increase the prior probability of detecting a valid association. ${ }^{55}$ The rationale for examining nonfunctional polymorphisms is that they may be in linkage disequilibrium with functional variants elsewhere in the gene, or even in nearby genes.

The strength of the candidate gene strategy is that it is hypothesis driven and, as such, the total number of candidate genes selected based on the known PK and PD of the drug will allow a prior level of significance to be set for the overall analysis, thereby making it easier to control for multiple 
testing. One limitation of this approach is that there are probably other unknown genes involved in the drug's metabolism or mechanisms of action, and these will be missed using a candidate gene strategy. ${ }^{47}$ Genome-wide approaches using single nucleotide polymorphisms (SNPs) may facilitate identification of pharmacogenomic 'hot spots' for drug responses. ${ }^{56}$ The two methodologies should be used together to maximise the identification of genetic predictors of ChEI drug responses. To our knowledge, no genome-wide association studies have been published to date on ChEI pharmacogenetics.

\section{Pharmacogenetics of cholinesterase inhibitors: Studies published to date}

\section{$A P O E$ and clinical response in $\mathrm{AD}$}

The APOE gene, located on chromosome 19q13.2, encodes human apolipoprotein E, a membranebound apoprotein involved in lipid metabolism. There are three allelic variants: $\varepsilon 2, \varepsilon 3$ and $\varepsilon 4$. These are determined by the amino acids at positions 112 and 158. A cysteine at both sites confers the $\varepsilon 2$ allele, while an arginine at both sites confers the $\varepsilon 4$ allele. Cysteine at codon 112 and arginine at codon 158 produce the most frequent allele, $\varepsilon 3$. In case-control studies, it has consistently been shown that the $\varepsilon 4$ allele frequency is higher in patients with $\mathrm{AD}$; there is a lower likelihood of developing $\mathrm{AD}$ in those with only the $\varepsilon 2$ allele. ${ }^{57,58}$ Furthermore, there is a gene dosage effect, whereby $\varepsilon 4$ homozygotes have an earlier age of onset than $\varepsilon 4$ heterozygotes, and individuals with the $\varepsilon 2$ allele have a later age of onset. ${ }^{57}$ The exact mechanism by which $A P O E \varepsilon 4$ contributes to the pathogenesis of $\mathrm{AD}$ is disputed, with alterations in $\mathrm{A} \beta$ aggregation, lipid metabolism and synaptic plasticity as three, possibly complementary, modes of action. ${ }^{59}$

In a small subgroup of AD patients from a large $\mathrm{RCT}^{30}{ }^{30}$ Poirier and colleagues ${ }^{60}$ were the first to demonstrate that $>80$ per cent of $\mathrm{AD}$ patients without $A P O E \& 4$ showed an improvement in response to tacrine after 30 weeks of treatment, whereas $>60$ per cent of $A P O E \varepsilon 4$-positive patients demonstrated no change, or worsening. These results have been supported by another study examining cognitive responses to tacrine. ${ }^{61}$ In a retrospective analysis of the entire RCT of Knapp et al., ${ }^{30}$ there was also a trend towards non-carriers of $A P O E \varepsilon 4$ having a better response than $\varepsilon 4$ carriers. This observed trend became significant in treated females without $A P O E \varepsilon 4$, compared with those with $A P O E \varepsilon 4 .^{62}$ Two other studies, one examining the donepezil response and one examining the galantamine response, showed the opposite effect, whereby the $A P O E \varepsilon 4$ allele was associated with an improved or stabilised cognitive response. ${ }^{63,64}$ Several negative associations of $A P O E$ polymorphism and responses to ChEIs (tacrine, donepezil, rivastigmine and galantamine) have also been reported, however; that is, there was no specific APOE genotype or allele which predicted clinical response to ChEIs. ${ }^{65-74}$

In a large RCT of patients with a diagnosis of amnestic mild cognitive impairment (MCI), thought to be a prodromal state of $\mathrm{AD}$, the presence of the $A P O E \& 4$ allele predicted a higher rate of conversion to $\mathrm{AD}$ in the overall sample at 36 months. ${ }^{75}$ Patients were randomised to either treatment with donepezil, vitamin E or placebo. Only treatment with donepezil in the first 12 months of the study was associated with a reduced conversion rate to $\mathrm{AD}$. This benefit of donepezil extended to 36 months in patients with either one or two APOE $\varepsilon 4$ alleles. Another large RCT of rivastigmine (the Investigation Into Delay to Diagnosis of Alzheimer's Disease with Exelon [InDDEx] study) to determine if it could delay conversion of MCI to AD demonstrated no efficacy and no differences in relation to $A P O E$ allele frequencies between treated- and placebo-arm patients. ${ }^{76}$

\section{Butyrylcholinesterase and clinical response in $A D$ and $L B D$}

$B C H E$ is located on chromosome $3 \mathrm{q} 26 .{ }^{39}$ Within the brain, BChE localises to neurones and glial and endothelial cells innervated by cholinergic projections. Much of the central activity of BChE is glial in origin, with highest densities found in deep cortical and subcortical regions. Although BChE-positive 
neurones occur less frequently than AChE-positive neurones, they are localised to specific neuronal groups within the amygdala, hippocampus and thalamus, which reciprocally innervate prefrontal cortical regions that are important in the regulation of apathy, attention and executive functions. BChE activity has been shown to increase with progression of $\mathrm{AD}$, while AChE activity decreases. ${ }^{27}$ This increase in BChE activity may alter $A \beta$ metabolism and facilitate transformation of benign plaques into more malignant forms. ${ }^{29}$ Given that rivastigmine is a highly selective BChE blocker, it may differentially improve attention and executive functions in $\mathrm{AD}$ and $\mathrm{LBD}$ compared with donepezil and galantamine. For a comprehensive review of the role of $\mathrm{BChE}$ in regulating attentional performance and executive functions in fronto-subcortical dementias and AD, please see Bullock and Lane. ${ }^{29}$

Two important BCHE polymorphisms have been studied in relation to ChEI therapy. These are the atypical variant (Aspartate70Glycine) and the K-variant (Alanine539Threonine). Each of these variants reduces the activity of BChE by about 30 per cent. $^{39}$ The K-variant has a population frequency of about 10 per cent, while that of the atypical variant is about 13 per cent, with some people carrying both variants. ${ }^{39}$ In subgroups of genotyped patients with a diagnosis of MCI or AD involved in clinical trials of rivastigmine, the frequency of the $\mathrm{K}$-variant was approximately 30 per cent. ${ }^{41,76}$ It is unclear whether this was due to an increased frequency of the $\mathrm{K}$-variant in the disease state or whether this was due to some other bias in the studies.

O'Brien et al. ${ }^{77}$ were the first to demonstrate that patients with DLB homozygous for the reduced-activity $\mathrm{K}$-variant and/or heterozygous for the atypical variant of $B C H E$ have preserved attentional performance and a slower rate of cognitive decline than those with the wild-type variant (WT). Furthermore, patients homozygous for the WT BCHE variant showed improved attention in response to rivastigmine, whereas individuals with the reduced-activity variants did not. This was proposed to be due to a ceiling effect in patients with the reduced-activity variants. ${ }^{77}$ In other words, patients possessing the reduced activity $\mathrm{K}$ - and/or atypical variants of $B C H E$ behaved as if they had a 'built-in' ChEI and therefore did not benefit from any further blockade by rivastigmine.

In a post-hoc analysis of a large, six-month, placebo-controlled trial of rivastigmine in PDD, it was demonstrated that individuals with the WT $B C H E$ variant in the placebo arm declined more rapidly in terms of measures of attention and executive functions, than those with the K-variant. ${ }^{29}$ Furthermore, only individuals with the WT BCHE variant-and not those with the $\mathrm{K}$-variant-responded favourably to rivastigmine on measures of attention and executive functions. ${ }^{29}$ This result is similar to that seen in the DLB study of O'Brien et al. ${ }^{77}$

In a large, double-blind, head-to-head trial of rivastigmine versus donepezil in patients with moderate $\mathrm{AD}$, rivastigmine had a modest benefit over donepezil in terms of improving function in patients' activities of daily living. ${ }^{78}$ This benefit was enhanced in patients with concomitant vascular risk factors, and in those with clinically suspected DLB and/or parkinsonian symptoms, supporting the hypothesis that $\mathrm{BChE}$ inhibition might be more beneficial for patients with fronto-subcortical dementias. Of note, this benefit was also significantly enhanced in those with WT BCHE and less apparent in those with the $\mathrm{K}$-variant, providing further evidence that BCHE polymorphism may alter responsiveness to rivastigmine. ${ }^{78}$

There is some evidence to suggest that younger patients with $\mathrm{AD}$ have a heavier burden of $\mathrm{A} \beta$ pathology than older patients, with a resulting more profound cholinergic deficit. ${ }^{29}$ Based on this premise, a subgroup of patients from Bullock et al. ${ }^{78}$ with AD, younger than 75 years, was retrospectively stratified and analysed according to whether they had the WT or K-variant of $B C H E .^{41}$ It was shown that the group of patients with the WT variant had better cognitive, behavioural and functional responses to rivastigmine than to donepezil, whereas similar responses to the two drugs were observed in the K-variant group. ${ }^{41}$ This was a subgroup analysis and would need replication in a large sample, but it could suggest that a beneficial response to rivastigmine may depend on genetic variation within 
$B C H E$, with WT individuals having a more favourable response and those with the $\mathrm{K}$-variant having a blunted response.

A post-hoc analysis of an RCT of rivastigmine (InDDEx) demonstrated that fewer women with MCI converted to dementia on rivastigmine treatment if they were homozygous for the BCHE $\mathrm{K}$-variant, compared to similar patients treated with placebo. ${ }^{76}$ Caution must be exercised in interpreting the results from such post-hoc, subgroup analyses, given that the biological basis for the observation may be weak and that the trials were neither designed for nor sufficiently powered to identify statistical differences.

\section{CYP2D6 and ChEIs}

In a small sample of AD patients treated with donepezil for at least three months, steady-state plasma concentrations and cognitive responsiveness was determined based on CYP2D6 genotype. $^{79}$ Although no poor metabolisers were identified, homozygous extensive and ultra-rapid metabolisers had a trend towards lower steady-state plasma concentrations than heterozygous extensive metabolisers. The heterozygous extensive metabolisers also had a better clinical outcome than homozygous extensive metabolisers and ultra-rapid metabolisers. To our knowledge, there have been no published studies examining the role of CYP2D6 polymorphism in response to galantamine to date.

\section{Pharmacogenetics of adverse effects to ChEIs}

Blockade of $\mathrm{AChE}$ and $\mathrm{BChE}$ by ChEIs in the peripheral autonomic nervous system may be responsible for the common dose-dependent side effects, including nausea, vomiting, anorexia and diarrhoea, ${ }^{11}$ although stimulation of brain stem centres may also play a role. Headache and dizziness are also relatively frequent and may reflect more central effects. Recently, a population-based cohort study of dementia patients using administrative data demonstrated that ChEIs are associated with an increased risk of syncope, bradycardia, pacemaker insertion and hip fracture. ${ }^{80}$ There is a paucity of literature examining the pharmacogenetics of adverse events to ChEIs. Future research on this topic is warranted and will be important in determining the true cost-effectiveness of these drugs.

Tacrine has been shown significantly to slow cognitive deterioration, as well as improve the behavioural symptoms of $\mathrm{AD}{ }^{81}$ Given its effectiveness, attempts have been made to identify genetic predictors of its hepatotoxicity, with the ultimate goal of improving its safety profile. Biotransformation of tacrine to reactive metabolites via CYP1A2 is thought to contribute to tacrine-induced liver dysfunction. Glutathione-S-transferase, a phase II enzyme, detoxifies the reactive intermediate via glutathione conjugation. ${ }^{82}$ Several studies have not shown an association between individual null genotypes of the glutathione-S-transferase mu (GSTM1) and theta (GSTT1) subtypes and tacrine hepatotoxicity in patients suffering from AD. ${ }^{83-85}$ One study demonstrated that combined null genotypes of GSTM1 and GSTT1 increased susceptibility to tacrine hepatotoxicity, however. ${ }^{86}$ Another study examining 241 SNPs across 19 candidate genes demonstrated an association between three SNPs in a drug transporter gene, $A B C B 4$, encoding the multidrug resistance protein 3 (MDR3), and elevated alanine aminotransferase (ALT) levels (an index of hepatic function), but this did not survive correction for multiple testing. ${ }^{87}$ Carr et al., ${ }^{88}$ using a hepatic gene expression microarray analysis in rats, administered a single dose of tacrine and demonstrated an elevation in several acute phase reactant proteins regulated by interleukin-6 (IL-6). Seventeen polymorphisms within IL-6 were studied in a group of $\mathrm{AD}$ patients treated with tacrine, and five of these were associated with elevated ALT levels. ${ }^{88}$ These preliminary findings need to be replicated and validated in larger studies.

One small study of galantamine response and adverse effects in $\mathrm{AD}$ demonstrated that APOE $\varepsilon 4$ carriers were more likely to have weight loss, as compared with non-carriers. ${ }^{73}$ Caution should be exercised in interpreting these results, since only 12 patients out of 202 had weight loss, making statistical power low. To our knowledge, to date there have been no studies published which examine the 
pharmacogenetics of the adverse effects to donepezil or rivastigmine.

\section{Defining the response to cholinesterase inhibitors: The challenges}

To date, Pharmacogenetic studies of ChEIs in AD and LBD have not demonstrated consistent results, making their reliability for predicting response low. This may be due to the complex, non-Mendelian nature of the phenotype of ChEI responsiveness and adverse effects. For example, polymorphism in one particular candidate gene may contribute to the phenotype of response in one particular group of patients, whereas polymorphism in different candidate genes may be operating in others (ie there is genetic heterogeneity). Alternatively, polymorphisms across several candidate genes may interact, and each may contribute a small proportion to the total variance observed in the phenotype of ChEI response (ie polygenic inheritance). Environmental and epigenetic factors probably also contribute to the complexity of this pharmacogenetic phenotype. Sample size and power limitations, issues with multiple testing and population stratification also confound results. ${ }^{49}$

Heterogeneity in clinical methodology may, however, play the most significant role. One of the main reasons for inconsistent results among studies of ChEIs is difficulty in defining what comprises a good response to these drugs. Phenotypes of cognitive, behavioural and functional responses to ChEIs and other neuropsychotropic drugs are extremely complex to measure because of a number of potential confounding factors. First, symptoms of dementia are subjectively described by either the patient or caregiver, or observed and interpreted by the clinician. Despite the use of 'objective' psychometric measures in quantifying these symptoms, ultimately the subjective nature of the initial description or interpretation will add 'noise' or error into any statistical analysis of response. Secondly, the high variability among clinicians/raters can further confound the determination of response. Thirdly, there are several different measures available to assess response, and this leads to heterogeneity in clinical assessment. The use of standardised neuropsychological measures may help to overcome these issues, as these probe the function of specific neural circuits involved in cognition and demonstrate high validity and reliability. Current instruments used, howeverparticularly the ADAS-Cog-are relatively insensitive in the executive cognitive domain, particularly attention, which may show the greatest responsiveness to ChEIs. ${ }^{89}$ Alternatively, the development of endophenotypes of the response to ChEIs, defined by CSF biomarkers and/or structural and functional neuroimaging, holds great promise in terms of bridging the large gap that exists between the basic underlying pathophysiological mechanisms and the ultimate clinical expression of the disease. ${ }^{90-92}$ Endophenotypes are latent traits (eg physiological, biochemical, cognitive or radiographic) that are related to the global phenotype of response to a drug, but are also more closely linked to underlying genetic factors. ${ }^{93}$ Importantly, a recent study confirmed the power of using endophenotypes for genetic association data in a cohort of $\mathrm{AD}$ patients, whereby the presence of $A P O E \varepsilon 4$ was associated most strongly with a quantitative score of $\mathrm{AD}$ brain pathology, followed by measures of cognitive function before death, and most weakly with clinical diagnosis of $\mathrm{AD} .^{94}$ Figure 1 is a schematic diagram demonstrating the use of endophenotypes in ChEI responsiveness.

A good endophenotype or biomarker of dementia progression should meet the following proposed criteria: 1) scientific plausibility; 2) ability to detect change with disease progression; 3) easily measurable, valid and reliable; 4) affordable; and 5) readily available. ${ }^{90,92}$ It is possible that endophenotypes of ChEI responsiveness in AD and LBD will be sensitive in demonstrating disease modification at the pathophysiological level (eg cholinesterase inhibition, cholinergic receptor density upregulation, increased metabolism, reduction in $A \beta$ ), thereby allowing for a reduced sample size in clinical trials of these drugs. ${ }^{92}$ We will therefore briefly review some examples of neuropsychological and neuroimaging endophenotypes that are potentially useful in pharmacogenetic studies of ChEI response. Other endophenotypes, not discussed in this paper, 
(A)
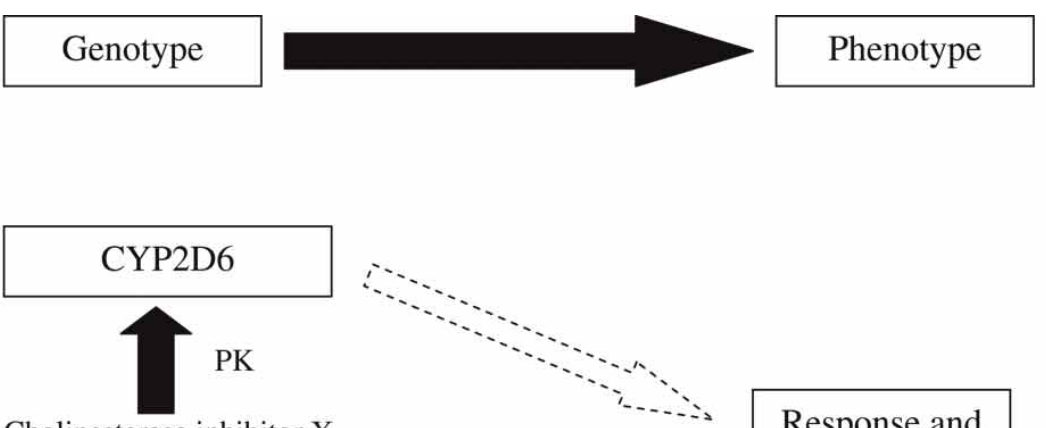

Cholinesterase inhibitor X

Response and

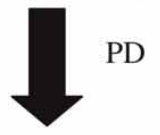

Acetylcholinesterase

adverse effects

(B)
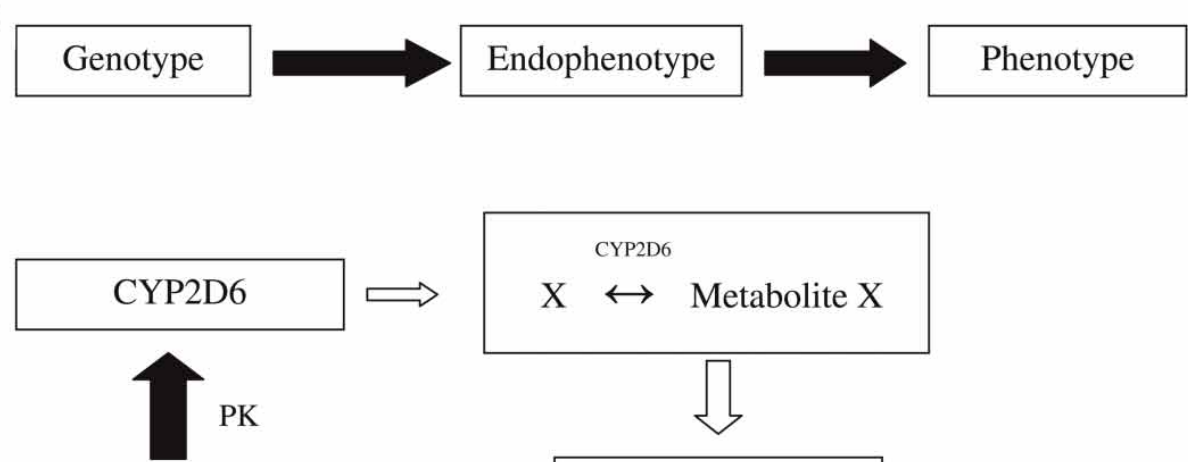

Cholinesterase inhibitor $\mathrm{X}$

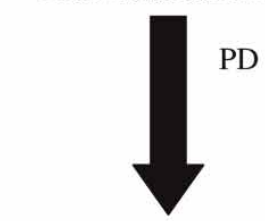

Acetylcholinesterase

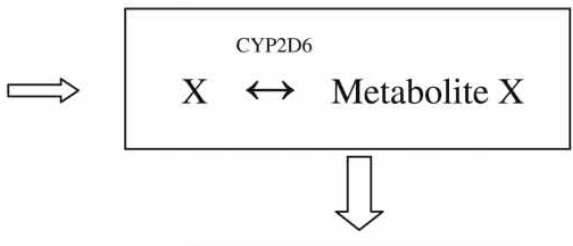

D
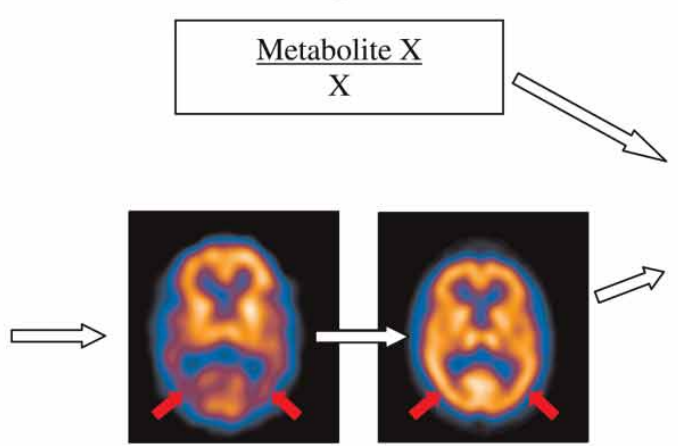

Response and adverse effects

Before X

After X

Figure I. Hypothetical genotype-phenotype correlations in response to cholinesterase inhibitor (ChEI) $X$ in Alzheimer's disease. The CYP2D6 enzyme is the major metaboliser in the pharmacokinetics of ChEl X, while acetylcholinesterase is the main pharmacodynamic target. (A) Polymorphisms in CYP2D6 and acetylcholinesterase are weakly associated with response and adverse effects to drug $X$ because there are many unknown steps linking the genotype to the phenotype. (B) Polymorphisms in CYP2D6 and acetylcholinesterase are strongly associated with endophenotypes, which are more closely linked to the drug response and adverse effect phenotype. The endophenotypes illustrated include: drug $\mathrm{X}$-to-metabolite $\mathrm{X}$ ratio, which provides an index of CYP2D6 activity and varies depending on which CYP2D6 genotype/allele is possessed; and a single photon emission computed tomography (SPECT) scan showing reduced perfusion in biparietal areas (red arrows), which hypothetically improves after treatment with drug $X$, depending on which genotype/allele is present. Orange colours on SPECT indicate higher perfusion, while purple/blue colours indicate reduced perfusion. Abbreviations: $\mathrm{PK}=$ pharmacokinetic; $\mathrm{PD}=$ pharmacodynamic. 
but which are 'up and coming' include serum and CSF biomarkers of cholinesterase activity and of $\mathrm{AD}$ itself (eg CSF A $\beta 1-42$ and Tau levels). ${ }^{95,96}$

\section{Cholinesterase inhibitor therapy: $A P O E$, $B C H E$, executive functions and hippocampal atrophy on magnetic resonance imaging}

Hippocampal atrophy is a magnetic resonance imaging (MRI) finding commonly associated with AD. ${ }^{97}$ Jack Jr. et al. ${ }^{98}$ found no relationship between hippocampal volumes on MRI and $A P O E$ genotype in controls and patients with $\mathrm{AD}$, although both were independently associated with the diagnosis of AD. Other studies have shown that the $A P O E \& 4$ allele is associated with accelerated rates of hippocampal atrophy in AD. ${ }^{99}$ This has been confirmed by more recent data from the Alzheimer's Disease Neuroimaging Initiative (ADNI), a large, multicentre, prospective study of AD, MCI and normal controls. The APOE $\varepsilon 4$ allele predicted more rapid hippocampal atrophy over a 12-month period in $\mathrm{AD}$ patients. ${ }^{100}$ In patients with a diagnosis of MCI, the presence of the $A P O E$ $\varepsilon 4$ allele was associated with more severe hippocampal atrophy and cognitive dysfunction than those without this allele. ${ }^{62,101}$ A post-hoc analysis of a large clinical trial of rivastigmine demonstrated that MCI patients in the placebo arm were more likely to convert to AD and have worse hippocampal volumetric loss if they were both $A P O E \varepsilon 4$ and $\mathrm{K}$-variant $B C H E$ carriers, compared with those without the $\varepsilon 4$ allele who also had at least one K-allele; pharmacogenetics data were not presented for the rivastigmine-treated group. ${ }^{102}$

Given that hippocampal atrophy can progress over a short time period in $\mathrm{AD}$, it might represent a good endophenotype of ChEI responsiveness. Although donepezil treatment reduced the rate of hippocampal atrophy and improved cognitive symptoms in AD patients, no interaction between the $A P O E$ genotype and donepezil treatment was observed. $^{103}$ In a group of MCI patients treated with donepezil, however, a trend was observed whereby hippocampal atrophy rates were slower in treated patients who were $A P O E \varepsilon 4$ carriers. ${ }^{104}$
Using MRI in patients with vascular dementia, $\mathrm{AD}$ and cognitive impairment (not demented), Swartz et al. ${ }^{105}$ were the first to demonstrate that the severity of ischaemic white matter hyperintensities strategically involving the ascending cholinergic pathways was inversely correlated with hippocampal width (measure of atrophy) across all groups. AD patients with moderate to severe ischaemic cholinergic pathway involvement, using a rating scale, performed worse on measures of executive function and visuospatial attention, despite similar measures of global impairment and memory dysfunction, compared with those with minimal involvement of these pathways ${ }^{105,106} \mathrm{AD}$ patients with involvement of the cholinergic pathways by ischaemic white matter disease on MRI showed less decline over one year on tests of executive function and working memory when started on ChEIs, compared with those without this ischaemic burden. ${ }^{107}$ Similar responses to ChEIs between the groups were observed for overall cognition, function and behaviour, and on memory, language and visuospatial tasks. ${ }^{107}$ That is to say, cognitive tasks probing executive functions appeared to be more sensitive in detecting potential beneficial responses to ChEIs than those probing other cognitive domains, and may be useful as an endophenotype. ${ }^{29}$

\section{Alterations in cerebral acetylcholinesterase activity and glucose metabolism using positron emission tomography in response to cholinesterase inhibitors}

Kuhl et al. ${ }^{108}$ demonstrated an approximate 50 per cent reduction in brain AChE activity in vivo using $\mathrm{N}-[11 \mathrm{C}]$ methylpiperidin-4-yl propionate ([11C] PMP) positron emission tomography (PET) after infusion of physostigmine, a ChEI, in normal individuals. AD patients demonstrated a reduction in this enzyme activity at baseline compared with controls. ${ }^{108}$ In patients with $\mathrm{AD}$, the degree of cortical AChE inhibition by donepezil correlated with patient improvement in cognitive function, particularly for measures of attention and executive functions. ${ }^{109}$ Patients with PD and PDD also demonstrated reduced brain AChE activity in vivo compared with 
controls using similar methods. The AChE activity correlated with cognitive measures of attention, working memory and executive functions. ${ }^{110}$

${ }^{18} \mathrm{~F}$-fluorodeoxyglucose (FDG)-PET is sensitive in detecting changes in cerebral glucose metabolism after treatment with ChEIs. The clinical benefits of metrifonate, an organophosphate-based ChEI never marketed due to respiratory side effects, were associated with increased metabolic activity in the left dorsolateral prefrontal network and bilateral temporal cortices in AD patients. ${ }^{111}$ Potkin et al. ${ }^{112}$ conducted a double-blind, placebo-controlled trial examining the clinical and metabolic effects of rivastigmine in 27 patients with mild to moderate AD. Good responders to rivastigmine had an increase in cortical metabolism (hippocampal and prefrontal regions) compared with non-responders and placebo.

\section{Alterations in brain perfusion using single photon emission computed tomography in response to cholinesterase inhibitor therapy}

Single photon emission computed tomography (SPECT) has also demonstrated utility in detecting changes in regional cerebral blood flow $(\mathrm{rCBF})$ in response to ChEI in AD. In 27 patients with mild $\mathrm{AD}$, enhanced $\mathrm{rCBF}$ in frontal, temporal and parietal areas correlated with psychometric improvement in responders versus non-responders to rivastigmine and in untreated patients. ${ }^{113}$ rCBF was preserved in the bilateral anterior cingulate gyri, right middle temporal gyrus, right inferior parietal lobule and prefrontal cortex in AD patients treated with donepezil for one year versus placebo. ${ }^{114}$ Similar findings with donepezil treatment of $\mathrm{AD}$ were shown in other studies. ${ }^{115,116}$ In a combined sample of AD and vascular dementia (VaD) patients, Lojkowska et al. ${ }^{117}$ observed that, in patients treated with rivastigmine, an increase in rCBF occurred in frontal regions for $\mathrm{VaD}$ and temporal regions for $\mathrm{AD}$ versus untreated patients. The beneficial effects of ChEI therapy in AD were accompanied by an increase in perfusion in the right anterior cingulate, dorsolateral prefrontal and temporoparietal areas bilaterally in another study. ${ }^{118}$ Donepezil also improved neuropsychiatric symptoms of dysphoria, apathy and anxiety in AD, which correlated with an accompanying increase in
$\mathrm{rCBF}$ in premotor areas and parietotemporal cortices in responders. ${ }^{119}$ Although participant numbers were relatively small, these findings suggest that perfusion changes on SPECT after treatment with ChEI could be a useful endophenotype with which to assess pharmacotherapeutic response in $\mathrm{AD}$, particularly given its wide availability.

With respect to ChEI therapy and change in rCBF via SPECT in LBD, initial case reports demonstrated a beneficial effect of donepezil that correlated well with a diffuse increase in CBF after treatment. ${ }^{120,121}$ In 29 patients with LBD, 14 with PDD and 15 with DLB, O'Brien et al. ${ }^{122}$ demonstrated that a decrease in hallucinations in response to ChEIs was associated with increased perfusion in the midline parietal region, including posterior cingulate, precuneus and superior parts of the cuneus. Another study in 20 patients with DLB demonstrated that after treatment with donepezil, Mini-Mental State Examination (MMSE) and Neuropsychiatric Inventory (NPI) scores improved over 12 weeks of therapy. Improvement in visual hallucinations was most significant, and this correlated with improved rCBF in bilateral occipital association cortices. ${ }^{123}$ Ceravalo et al. ${ }^{124}$ examined cognitive responsiveness to rivastigmine and donepezil and brain perfusion using SPECT in 19 patients with PDD. After six months of treatment, cognitive scores improved-mostly in domains of concentration and executive functions-and this correlated with increased $\mathrm{rCBF}$ in bilateral anterior cingulate, as well as superior, middle and inferior frontal gyri, areas, which are implicated in tasks involving attention and executive functions.

Both PET and SPECT studies are able to detect change before and after ChEI therapy in $\mathrm{AD}$ and LBD. Although PET has higher spatial resolution than SPECT, SPECT radioisotopes have a longer half-life and are cheaper, making it more widely available and potentially more cost-effective to use in clinical studies of dementia and ChEI response endophenotypes. ${ }^{125}$

\section{Conclusions and future directions}

Clarifying the pharmacogenetic profile of individual ChEIs in the symptomatic treatment of AD and 
LBD will remain an important line of investigation, as these drugs will probably continue to play a role in the management of these devastating disorders in the foreseeable future. To date, genetic polymorphism within $A P O E$ and $B C H E$ has been shown to contribute to inter-individual variability in response to ChEIs in these conditions, although the findings are not always consistent across studies. A promising line of research includes the use of endophenotypes of the response to ChEIs, which should facilitate a better understanding of the mechanisms of action of these drugs and their relationship to the underlying pharmacogenetic predisposition. As reliable and more robust endophenotypes of AD and LBD are discovered, newer drugs can be tested in smaller samples, which, theoretically, could facilitate faster movement of these agents down the drug development pipeline, bringing them to market sooner.

Future prospective studies of ChEI response and adverse effects should be designed specifically for the identification of genetic susceptibility to these drug-related traits, taking into account allele frequencies for the candidate genes being examined a priori. To date, studies have used samples obtained from prospective or retrospective clinical trials with post-hoc analysis of genetic hypotheses, which is far from optimal. Furthermore, multiple loci across the candidate genes should be examined to construct haplotypes which may be associated with ChEI response and adverse effects. Interactions between candidate gene polymorphisms should also be explored, given that these phenotypes are probably polygenic.

In the future, this pharmacogenetics research has the potential to lead to simple, fast and inexpensive DNA tests to identify ChEI response status and predisposition to side effects in patients suffering from $\mathrm{AD}$ and LBD. This would equip physicians with useful information to assist them in making a decision about which drug to use, at what dose and in whom to initiate treatment. This 'personalised pharmacotherapy' will have significant potential to spare the patient from side effects and maximise a positive response to the medication. Furthermore, patients can be sub-grouped for research and clinical trials based on their pharmacogenetic profile, which may salvage drugs which would fail in the overall clinical population. ${ }^{126}$ This research may also aid in elucidating the mechanism of action of ChEIs, and thus may help in the design of new, more efficacious therapeutic agents. Additionally, this research will contribute to a better understanding of the pathogenesis of these complex diseases.

\section{Acknowledgments}

M.M. is supported by a Clinician-Scientist Award from the Canadian Institutes of Health Research (CIHR).

\section{References}

1. Blennow, K., de Leon, M.J. and Zetterberg, H. (2006), 'Alzheimer's disease', Lancet Vol. 368, pp. 387-403.

2. McKeith, I., Mintzer, J., Aarsland, D., Burn, D. et al. (2004), 'Dementia with Lewy bodies', Lancet Neurol. Vol. 3, pp. 19-28.

3. Rahkonen, T., Eloniemi-Sulkava, U., Rissanen, S., Vatanen, A. et al. (2003), 'Dementia with Lewy bodies according to the consensus criteria in a general population aged 75 years or older', J. Neurol. Neurosurg. Psychiatry Vol. 74, pp. 720-724.

4. Farlow, M. (2007), 'Alzheimer's disease', Continuum Vol. 13, pp. 39-68.

5. Dekosky, S.T. (2001), 'Epidemiology and pathophysiology of Alzheimer's disease', Clin. Cornerstone Vol. 3, pp. 15-26.

6. Centers for Disease Control and Prevention (2003), 'Public health and aging: Trends in aging — United States and worldwide', JAMA Vol. 289, pp. $1371-1373$

7. Ferri, C.P., Prince, M., Brayne, C., Brodaty, H. et al. (2005), 'Global prevalence of dementia: A Delphi consensus study', Lancet Vol. 366, pp. 2112-2117.

8. Qiu, C., De Ronchi, D. and Fratiglioni, L. (2007), 'The epidemiology of the dementias: An update', Curr. Opin. Psychiatry Vol. 20, pp. $380-385$.

9. Wimo, A., Winblad, B., Aguero-Torres, H. and von Strauss, E. (2003), 'The magnitude of dementia occurrence in the world', Alzheimer Dis. Assoc. Disord. Vol. 17, pp. 63-67.

10. Lanctot, K.L., Herrmann, N., Yau, K.K., Khan, LR. et al. (2003), 'Efficacy and safety of cholinesterase inhibitors in Alzheimer's disease: A meta-analysis', CMAJ Vol. 169, pp. 557-564.

11. Loveman, E., Green, C., Kirby, J., Takeda, A. et al. (2006), 'The clinical and cost-effectiveness of donepezil, rivastigmine, galantamine and memantine for Alzheimer's disease', Health Technol. Assess. Vol. 10, pp. iii-iv, ix-xi, $1-160$.

12. Masters, C.L. and Beyreuther, K. (2006), 'Alzheimer's centennial legacy: Prospects for rational therapeutic intervention targeting the Abeta amyloid pathway', Brain Vol. 129, pp. 2823-2839.

13. Becker, R.E., Greig, N.H. and Giacobini, E. (2008), "Why do so many drugs for Alzheimer's disease fail in development? Time for new methods and new practices?', J. Alzheimers Dis. Vol. 15, pp. 303-325.

14. McKhann, G., Drachman, D., Folstein, M., Katzman, R. et al. (1984), 'Clinical diagnosis of Alzheimer's disease: Report of the NINCDS-ADRDA Work Group under the auspices of Department of Health and Human Services Task Force on Alzheimer's Disease', Neurology Vol. 34, pp. 939-944.

15. Dubois, B., Feldman, H.H., Jacova, C., Dekosky, S.T. et al. (2007), 'Research criteria for the diagnosis of Alzheimer's disease: Revising the NINCDS-ADRDA criteria', Lancet Neurol. Vol. 6, pp. 734-746. 
16. Braak, H. and Braak, E. (1991), 'Neuropathological stageing of Alzheimer-related changes', Acta Neuropathol. Vol. 82, pp. 239-259.

17. Camicioli, R. and Fisher, N. (2004), 'Progress in clinical neurosciences: Parkinson's disease with dementia and dementia with Lewy bodies', Can. J. Neurol. Sci. Vol. 31, pp. 7-21.

18. Collerton, D., Burn, D., McKeith, I. and O'Brien, J. (2003), 'Systematic review and meta-analysis show that dementia with Lewy bodies is a visual-perceptual and attentional-executive dementia', Dement. Geriatr. Cogn. Disord. Vol. 16, pp. 229-237.

19. McKeith, I.G., Dickson, D.W., Lowe, J., Emre, M. et al. (2005), 'Diagnosis and management of dementia with Lewy bodies: Third report of the DLB Consortium', Neurology Vol. 65, pp. 1863-1872.

20. Samii, A., Nutt, J.G. and Ransom, B.R. (2004), 'Parkinson's disease', Lancet Vol. 363, pp. 1783-1793.

21. Emre, M. (2003), 'Dementia associated with Parkinson's disease', Lancet Neurol. Vol. 2, pp. 229-237.

22. Aarsland, D., Ballard, C.G. and Halliday, G. (2004), 'Are Parkinson's disease with dementia and dementia with Lewy bodies the same entity?', J. Geriatr. Psychiatry Neurol. Vol. 17, pp. 137-145.

23. Duda, J.E. (2004), 'Pathology and neurotransmitter abnormalities of dementia with Lewy bodies', Dement. Geriatr. Cogn. Disord. Vol. 17 (Suppl. 1), pp. 3-14.

24. Hansen, L., Salmon, D., Galasko, D., Masliah, E. et al. (1990), 'The Lewy body variant of Alzheimer's disease: A clinical and pathologic entity', Neurolog $\gamma$ Vol. 40, pp. 1-8.

25. Bartus, R.T., Dean, R.L. III, Beer, B. and Lippa, A.S. (1982), 'The cholinergic hypothesis of geriatric memory dysfunction', Science Vol. 217, pp. $408-414$

26. Cummings, J.L. and Back, C. (1998), 'The cholinergic hypothesis of neuropsychiatric symptoms in Alzheimer's disease', Am. J. Geriatr. Psychiatry Vol. 6 (2 Suppl. 1), pp. S64-S78.

27. Perry, E.K., Perry, R.H., Blessed, G. and Tomlinson, B.E. (1978), 'Changes in brain cholinesterases in senile dementia of Alzheimer type', Neuropathol. Appl. Neurobiol. Vol. 4, pp. 273-277.

28. Tiraboschi, P., Hansen, L.A., Alford, M., Sabbagh, M.N. et al. (2000), 'Cholinergic dysfunction in diseases with Lewy bodies', Neurology Vol. 54, pp. 407-411.

29. Bullock, R. and Lane, R. (2007), 'Executive dyscontrol in dementia, with emphasis on subcortical pathology and the role of butyrylcholinesterase', Curr. Alzheimer Res. Vol. 4, pp. 277-293.

30. Knapp, M.J., Knopman, D.S., Solomon, P.R., Pendlebury, W.W. et al. (1994), 'A 30-week randomized controlled trial of high-dose tacrine in patients with Alzheimer's disease. The Tacrine Study Group', JAMA Vol. 271, pp. 985-991.

31. Watkins, P.B., Zimmerman, H.J., Knapp, M.J., Gracon, S.I. et al. (1994), 'Hepatotoxic effects of tacrine administration in patients with Alzheimer's disease', JAMA Vol. 271, pp. 992-998.

32. Reisberg, B., Doody, R., Stoffler, A., Schmitt, F. et al. (2003), 'Memantine in moderate-to-severe Alzheimer's disease', N. Engl. J. Med. Vol. 348, pp. 1333-1341.

33. Greenblatt, D.J., Harmatz, J.S., von Moltke, L.L. and Shader, R.I. (1995), 'Pharmacokinetics and pharmacodynamics' in: Bloom, F.E. and Kupfer, D.J. (eds), Psychopharmacology: The Fourth Generation of Progress, New York, NY, Raven Press, pp. 849-858.

34. Rowland, M. and Tozer, T.N. (1995), Clinical Pharmacokinetics. Concepts and Applications (3rd edn), Philadelphia, PA, Williams \& Wilkins.

35. Kalow, W. (1997), 'Pharmacogenetics in biological perspective', Pharmacol. Rev. Vol. 49, pp. 369-379.

36. Jann, M.W., Shirley, K.L. and Small, G.W. (2002), 'Clinical pharmacokinetics and pharmacodynamics of cholinesterase inhibitors', Clin. Pharmacokinet. Vol. 41, pp. 719-739.

37. Scarpini, E., Scheltens, P. and Feldman, H. (2003), 'Treatment of Alzheimer's disease: Current status and new perspectives', Lancet Neurol. Vol. 2, pp. 539-547.

38. Mannens, G.S., Snel, C.A., Hendrickx, J., Verhaeghe, T. et al. (2002), 'The metabolism and excretion of galantamine in rats, dogs, and humans', Drug Metab. Dispos. Vol. 30, pp. 553-563.
39. Darvesh, S., Hopkins, D.A. and Geula, C. (2003), 'Neurobiology of butyrylcholinesterase', Nat. Rev. Neurosci. Vol. 4, pp. 131-138.

40. Soreq, H. and Seidman, S. (2001), 'Acetylcholinesterase - New roles for an old actor', Nat. Rev. Neurosci. Vol. 2, pp. 294-302.

41. Blesa, R., Bullock, R., He, Y., Bergman, H. et al. (2006), 'Effect of butyrylcholinesterase genotype on the response to rivastigmine or donepezil in younger patients with Alzheimer's disease', Pharmacogenet. Genomics Vol. 16, pp. 771-774.

42. Touchon, J., Bergman, H., Bullock, R., Rapatz, G. et al. (2006), 'Response to rivastigmine or donepezil in Alzheimer's patients with symptoms suggestive of concomitant Lewy body pathology', Curr. Med. Res. Opin. Vol. 22, pp. 49-59.

43. Michaelis, M.L. (2003), 'Drugs targeting Alzheimer's disease: Some things old and some things new', J. Pharmacol. Exp. Ther. Vol. 304, pp. 897-904.

44. Auriacombe, S., Pere, J.J., Loria-Kanza, Y. and Vellas, B. (2002), 'Efficacy and safety of rivastigmine in patients with Alzheimer's disease who failed to benefit from treatment with donepezil', Curr. Med. Res. Opin. Vol. 18, pp. 129-138.

45. Cacabelos, R. (2007), 'Donepezil in Alzheimer's disease: From conventional trials to pharmacogenetics', Neuropsychiatr. Dis. Treat. Vol. 3, pp. $303-333$.

46. Mayeux, R. and Sano, M. (1999), 'Treatment of Alzheimer's disease', N. Engl. J. Med. Vol. 341, pp. 1670-1679.

47. Evans, W.E. and McLeod, H.L. (2003), 'Pharmacogenomics — Drug disposition, drug targets, and side effects', N. Engl. J. Med. Vol. 348, pp. $538-549$.

48. Evans, W.E. and Relling, M.V. (2007), 'Moving towards individualized medicine with pharmacogenomicsC', Nature Vol. 429, pp. 464-468.

49. Masellis, M., Basile, V.S., Ozdemir, V., Meltzer, H.Y. et al. (2000), 'Pharmacogenetics of antipsychotic treatment: Lessons learned from clozapine', Biol. Psychiatry Vol. 47, pp. 252-266.

50. Kalow, W. (2004), 'Atypical plasma cholinesterase. A personal discovery story: A tale of three cities', Can. J. Anaesth. Vol. 51, pp. 206-211.

51. Kalow, W. (1956), 'Familial incidence of low pseudocholinesterase level', Lancet Vol. 2, pp. 576-577.

52. Lehmann, H. and Ryan, E. (1956), 'The familial incidence of low pseudocholinesterase level', Lancet Vol. 2, p.126.

53. Mohs, R.C., Rosen, W.G. and Davis, K.L. (1983), 'The Alzheimer's disease assessment scale: An instrument for assessing treatment efficacy', Psychopharmacol. Bull. Vol. 19, pp. 448-450.

54. Crowe, RR. (1993), 'Candidate genes in psychiatry: An epidemiological perspective', Am. J. Med. Genet. Vol. 48, pp. 74-77.

55. Malhotra, A.K. and Goldman, D. (1999), 'Benefits and pitfalls encountered in psychiatric genetic association studies', Biol. Psychiatry Vol. 45, pp. 544-550.

56. Regalado, A. (1999), 'Inventing the pharmacogenomics business', Am. J. Health Syst. Pharm. Vol. 56, pp. 40-50.

57. St George-Hyslop, P.H. (2000), 'Molecular genetics of Alzheimer's disease', Biol. Psychiatry Vol. 47, pp. 183-199.

58. Shobab, L.A., Hsiung, G.Y. and Feldman, H.H. (2005), 'Cholesterol in Alzheimer's disease', Lancet Neurol. Vol. 4, pp. 841-852.

59. St.George-Hyslop, P. (2008), 'Genetics of dementia', Continuum Vol. 14, pp. 29-48.

60. Poirier, J., Delisle, M.C., Quirion, R., Aubert, I. et al. (1995), 'Apolipoprotein E4 allele as a predictor of cholinergic deficits and treatment outcome in Alzheimer disease', Proc. Natl. Acad. Sci. USA Vol. 92, pp. $12260-12264$.

61. Sjogren, M., Hesse, C., Basun, H., Kol, G. et al. (2001), 'Tacrine and rate of progression in Alzheimer's disease - Relation to ApoE allele genotype', J. Neural Transm. Vol. 108, pp. 451-458.

62. Farlow, M.R., Lahiri, D.K., Poirier, J., Davignon, J. et al. (1998), 'Treatment outcome of tacrine therapy depends on apolipoprotein genotype and gender of the subjects with Alzheimer's disease', Neurology Vol. 50, pp. 669-677. 
63. Babic, T., Mahovic, L.D., Sertic, J., Petrovecki, M. et al. (2004), 'ApoE genotyping and response to galanthamine in Alzheimer's disease - A real life retrospective study', Coll. Antropol. Vol. 28, pp. 199-204.

64. Bizzarro, A., Marra, C., Acciarri, A., Valenza, A. et al. (2005), 'Apolipoprotein E epsilon4 allele differentiates the clinical response to donepezil in Alzheimer's disease', Dement. Geriatr. Cogn. Disord. Vol 20, pp. 254-261.

65. Aerssens, J., Raeymaekers, P., Lilienfeld, S., Geerts, H. et al. (2001), 'APOE genotype: No influence on galantamine treatment efficacy nor on rate of decline in Alzheimer's disease', Dement. Geriatr. Cogn. Disord. Vol. 12, pp. 69-77

66. Almkvist, O., Darreh-Shori, T., Stefanova, E., Spiegel, R. et al. (2004), 'Preserved cognitive function after 12 months of treatment with rivastigmine in mild Alzheimer's disease in comparison with untreated AD and MCI patients', Eur. J. Neurol. Vol. 11, pp. 253-261.

67. Farlow, M., Lane, R., Kudaravalli, S. and He, Y. (2004), 'Differential qualitative responses to rivastigmine in APOE epsilon4 carriers and noncarriers', Pharmacogenomics J. Vol. 4, pp. 332-335.

68. Greenberg, S.M., Tennis, M.K., Brown, L.B., Gomez-Isla, T. et al. (2000), 'Donepezil therapy in clinical practice: A randomized crossover study', Arch. Neurol. Vol. 57, pp. 94-99.

69. MacGowan, S.H., Wilcock, G.K. and Scott, M. (1998), 'Effect of gender and apolipoprotein $\mathrm{E}$ genotype on response to anticholinesterase therapy in Alzheimer's disease', Int. J. Geriatr. Psychiatry Vol. 13, pp. 625-630.

70. Raskind, M.A., Peskind, E.R., Wessel, T. and Yuan, W. (2000), 'Galantamine in AD: A 6-month randomized, placebo-controlled tria with a 6-month extension. The Galantamine USA-1 Study Group', Neurology Vol. 54, pp. 2261-2268.

71. Rigaud, A.S., Traykov, L., Caputo, L., Guelfi, M.C. et al. (2000), 'The apolipoprotein E epsilon4 allele and the response to tacrine therapy in Alzheimer's disease', Eur. J. Neurol. Vol. 7, pp. 255-258.

72. Rigaud, A.S., Traykov, L., Latour, F., Couderc, R. et al. (2002), 'Presence or absence of at least one epsilon 4 allele and gender are not predictive for the response to donepezil treatment in Alzheimer's disease', Pharmacogenetics Vol. 12, pp. 415-420.

73. Suh, G.H., Jung, H.Y., Lee, C.U., Oh, B.H. et al. (2006), 'Effect of the apolipoprotein E epsilon4 allele on the efficacy and tolerability of galantamine in the treatment of Alzheimer's disease', Dement. Geriatr. Cogn. Disord. Vol. 21, pp. 33-39.

74. Wallin, A.K., Hansson, O., Blennow, K., Londos, E. et al. (2009), 'Can CSF biomarkers or pre-treatment progression rate predict response to cholinesterase inhibitor treatment in Alzheimer's disease?', Int. J. Geriatr Psychiatry Vol. 24, pp. 638-647.

75. Petersen, R.C., Thomas, R.G., Grundman, M., Bennett, D. et al. (2005), 'Vitamin E and donepezil for the treatment of mild cognitive impairment', N. Engl. J. Med. Vol. 352, pp. 2379-2388.

76. Feldman, H.H., Ferris, S., Winblad, B., Sfikas, N. et al. (2007), 'Effect of rivastigmine on delay to diagnosis of Alzheimer's disease from mild cognitive impairment: The InDDEx study', Lancet Neurol. Vol. 6, pp. 501-512.

77. O’Brien, K.K., Saxby, B.K., Ballard, C.G., Grace, J. et al. (2003), 'Regulation of attention and response to therapy in dementia by butyrylcholinesterase', Pharmacogenetics Vol. 13, pp. 231-239.

78. Bullock, R., Touchon, J., Bergman, H., Gambina, G. et al. (2005), 'Rivastigmine and donepezil treatment in moderate to moderatelysevere Alzheimer's disease over a 2-year period', Curr. Med. Res. Opin. Vol. 21, pp. 1317-1327.

79. Varsaldi, F., Miglio, G., Scordo, M.G., Dahl, M.L. et al. (2006), 'Impact of the CYP2D6 polymorphism on steady-state plasma concentrations and clinical outcome of donepezil in Alzheimer's disease patients', Eur. J. Clin. Pharmacol. Vol. 62, pp. 721-726.

80. Gill, S.S., Anderson, G.M., Fischer, H.D., Bell, C.M. et al. (2009), 'Syncope and its consequences in patients with dementia receiving cholinesterase inhibitors: A population-based cohort study', Arch. Intern. Med. Vol. 169, pp. 867-873.

81. Summers, W.K., Majovski, L.V., Marsh, G.M., Tachiki, K. et al. (1986), 'Oral tetrahydroaminoacridine in long-term treatment of senile dementia, Alzheimer type', N. Engl. J. Med. Vol. 315, pp. 1241-1245.
82. Woolf, T.F., Pool, W.F., Bjorge, S.M., Chang, T. et al. (1993), 'Bioactivation and irreversible binding of the cognition activator tacrine using human and rat liver microsomal preparations. Species difference', Drug Metab. Dispos. Vol. 21, pp. 874-882.

83. Becquemont, L., Lecoeur, S., Simon, T., Beaune, P. et al. (1997), 'Glutathione S-transferase theta genetic polymorphism might influence tacrine hepatotoxicity in Alzheimer's patients', Pharmacogenetics Vol. 7, pp. $251-253$.

84. De Sousa, M, Pirmohamed, M., Kitteringham, N.R., Woolf, T. et al (1998), 'No association between tacrine transaminitis and the glutathione transferase theta genotype in patients with Alzheimer's disease', Pharmacogenetics Vol. 8, pp. 353-355.

85. Green, V.J., Pirmohamed, M., Kitteringham, N.R., Knapp, M.J. et al. (1995), 'Glutathione S-transferase mu genotype (GSTM1*0) in Alzheimer's patients with tacrine transaminitis', Br. J. Clin. Pharmacol. Vol. 39, pp. 411-415.

86. Simon, T., Becquemont, L., Mary-Krause, M., de Waziers, I. et al. (2000), 'Combined glutathione-S-transferase M1 and T1 genetic polymorphism and tacrine hepatotoxicity', Clin. Pharmacol. Ther. Vol. 67, pp. $432-437$

87. Alfirevic, A., Mills, T., Carr, D., Barratt, B.J. et al. (2007), 'Tacrine-induced liver damage: An analysis of 19 candidate genes', Pharmacogenet. Genomics Vol. 17, pp. 1091-1100.

88. Carr, D.F., Alfirevic, A., Tugwood, J.D., Barratt, B.J. et al. (2007), 'Molecular and genetic association of interleukin-6 in tacrine-induced hepatotoxicity', Pharmacogenet. Genomics Vol. 17, pp. 961-972.

89. Behl, P., Lanctot, K.L., Streiner, D.L., Guimont, I. et al. (2006), 'Cholinesterase inhibitors slow decline in executive functions, rather than memory, in Alzheimer's disease: A 1-year observational study in the Sunnybrook dementia cohort', Curr. Alzheimer Res. Vol. 3, pp. 147-156.

90. Chertkow, H. and Black, S. (2007), 'Imaging biomarkers and their role in dementia clinical trials', Can. J. Neurol. Sci. Vol. 34 (Suppl. 1), pp. S77-S83.

91. Hariri, A.R. and Weinberger, D.R. (2003), 'Imaging genomics', Br. Med. Bull. Vol. 65, pp. 259-270.

92. Thal, L.J., Kantarci, K., Reiman, E.M., Klunk, W.E. et al. (2006), 'The role of biomarkers in clinical trials for Alzheimer disease', Alzheimer Dis. Assoc. Disord. Vol. 20, pp. 6-15.

93. Leboyer, M., Bellivier, F., Nosten-Bertrand, M., Jouvent, R. et al. (1998), 'Psychiatric genetics: Search for phenotypes', (1998), Trends Neurosci. Vol. 21, pp. 102-105

94. Bennett, D.A., De Jager, P.L., Leurgans, S.E. and Schneider, J.A. (2009), 'Neuropathologic intermediate phenotypes enhance association to Alzheimer susceptibility alleles', Neurology Vol. 72, pp. 1495-1503.

95. Darreh-Shori, T., Kadir, A., Almkvist, O., Grut, M. et al. (2008), 'Inhibition of acetylcholinesterase in CSF versus brain assessed by 11C-PMP PET in AD patients treated with galantamine', Neurobiol. Aging Vol. 29, pp. 168-184.

96. Shaw, L.M., Vanderstichele, H., Knapik-Czajka, M., Clark, C.M. et al. (2009), 'Cerebrospinal fluid biomarker signature in Alzheimer's disease neuroimaging initiative subjects', Ann. Neurol. Vol. 65, pp. 403-413.

97. Kesslak, J.P., Nalcioglu, O. and Cotman, C.W. (1991), 'Quantification of magnetic resonance scans for hippocampal and parahippocampal atrophy in Alzheimer's disease', Neurology Vol. 41, pp. 51-54.

98. Jack, C.R., Jr, Petersen, R.C., Xu, Y.C., O’Brien, P.C. et al. (1998), 'Hippocampal atrophy and apolipoprotein $\mathrm{E}$ genotype are independently associated with Alzheimer's disease', Ann. Neurol. Vol. 43, pp. 303-310.

99. Mori, S. (2002), 'Responses to donepezil in Alzheimer's disease and Parkinson's disease', Ann. NY Acad. Sci. Vol. 977, pp. 493-500.

100. Schuff, N., Woerner, N., Boreta, L., Kornfield, T. et al. (2009), 'MRI of hippocampal volume loss in early Alzheimer's disease in relation to ApoE genotype and biomarkers', Brain Vol. 132, pp. 1067-1077.

101. van de Pol, L.A., van der Flier, W.M., Korf, E.S. and Fox, N.C. (2007), 'Baseline predictors of rates of hippocampal atrophy in mild cognitive impairment', Neurology Vol. 69, pp. 1491-1497. 
102. Lane, R., Feldman, H.H., Meyer, J., He, Y. et al. (2008), 'Synergistic effect of apolipoprotein E epsilon4 and butyrylcholinesterase K-variant on progression from mild cognitive impairment to Alzheimer's disease', Pharmacogenet. Genomics Vol. 18, pp. 289-298.

103. Hashimoto, M., Kazui, H., Matsumoto, K., Nakano, Y. et al. (2005), 'Does donepezil treatment slow the progression of hippocampal atrophy in patients with Alzheimer's disease?', Am. J. Psychiatry Vol. 62, pp. 676-682.

104. Jack, C.R., Jr, Petersen, R.C., Grundman, M., Jin, S. et al. (2008), 'Longitudinal MRI findings from the vitamin $\mathrm{E}$ and donepezil treatment study for MCI', Neurobiol. Aging Vol. 29, pp. 1285-1295.

105. Swartz, R.H., Sahlas, D.J. and Black, S.E. (2003), 'Strategic involvement of cholinergic pathways and executive dysfunction: Does location of white matter signal hyperintensities matter?', J. Stroke Cerebrovasc. Dis. Vol. 12(1), pp. 29-36.

106. Bocti, C., Swartz, R.H., Gao, F.Q., Sahlas, D.J. et al. (2005), 'A new visual rating scale to assess strategic white matter hyperintensities within cholinergic pathways in dementia', Stroke Vol. 36, pp. 2126-2131.

107. Behl, P., Bocti, C., Swartz, R.H., Gao, F. et al. (2007), 'Strategic subcortical hyperintensities in cholinergic pathways and executive function decline in treated Alzheimer patients', Arch. Neurol. Vol. 64, pp. $266-272$.

108. Kuhl, D.E., Koeppe, R.A., Minoshima, S., Snyder, S.E. et al. (1999), 'In vivo mapping of cerebral acetylcholinesterase activity in aging and Alzheimer's disease', Neurology Vol. 52, pp. 691-699.

109. Shinotoh, H., Aotsuka, A., Fukushi, K., Nagatsuka, S. et al. (2001), 'Effect of donepezil on brain acetylcholinesterase activity in patients with AD measured by PET', Neurology Vol. 56, pp. 408-410.

110. Bohnen, N.I., Kaufer, D.I., Hendrickson, R., Ivanco, L.S. et al. (2006), 'Cognitive correlates of cortical cholinergic denervation in Parkinson's disease and parkinsonian dementia', J. Neurol. Vol. 253, pp. 242-247.

111. Mega, M.S., Cummings, J.L., O’Connor, S.M., Dinov, I.D. et al. (2001), 'Cognitive and metabolic responses to metrifonate therapy in Alzheimer disease', Neuropsychiatry Neuropsychol. Behav. Neurol. Vol. 14, pp. 63-68

112. Potkin, S.G., Anand, R., Fleming, K., Alva, G. et al. (2001), 'Brain metabolic and clinical effects of rivastigmine in Alzheimer's disease', Int. J. Neuropsychopharmacol. Vol. 4, pp. 223-230.

113. Venneri, A., Shanks, M.F., Staff, R.T., Pestell, S.J. et al. (2002), 'Cerebral blood flow and cognitive responses to rivastigmine treatment in Alzheimer's disease', Neuroreport Vol. 13, pp. 83-87.
114. Nakano, S., Asada, T., Matsuda, H., Uno, M. et al. (2001), 'Donepezil hydrochloride preserves regional cerebral blood flow in patients with Alzheimer's disease', J. Nucl. Med. Vol. 42, pp. 1441-1445.

115. Nobili, F., Koulibaly, M., Vitali, P., Migneco, O. et al. (2002), 'Brain perfusion follow-up in Alzheimer's patients during treatment with acetylcholinesterase inhibitors', J. Nucl. Med. Vol. 43, pp. 983-990.

116. Nobili, F., Vitali, P., Canfora, M., Girtler, N. et al. (2002), 'Effects of long-term donepezil therapy on rCBF of Alzheimer's patients', Clin. Neurophysiol. Vol. 113, pp. 1241-1248.

117. Lojkowska, W., Ryglewicz, D., Jedrzejczak, T., Minc, S. et al. (2003), 'The effect of cholinesterase inhibitors on the regional blood flow in patients with Alzheimer's disease and vascular dementia', J. Neurol. Sci. Vol. 216, pp. 119-126.

118. Ceravolo, R., Volterrani, D., Tognoni, G., Dell'Agnello, G. et al. (2004), 'Cerebral perfusional effects of cholinesterase inhibitors in Alzheimer disease', Clin. Neuropharmacol. Vol. 27, pp. 166-170.

119. Tanaka, M., Namiki, C., Thuy, D.H., Yoshida, H. et al. (2004), 'Prediction of psychiatric response to donepezil in patients with mild to moderate Alzheimer's disease', J. Neurol. Sci. Vol. 225, pp. 135-141.

120. Imamura, K., Wada-Isoe, K., Kowa, H., Tanabe, Y. et al. (2008), 'The effect of donepezil on increased regional cerebral blood flow in the posterior cingulate cortex of a patient with Parkinson's disease dementia', Neurocase Vol. 14, pp. 271-275.

121. Mori, E., Lee, K., Yasuda, M., Hashimoto, M. et al. (2002), 'Accelerated hippocampal atrophy in Alzheimer's disease with apolipoprotein E epsilon4 allele', Ann. Neurol. Vol. 51, pp. 209-214.

122. O'Brien, J.T., Firbank, M.J., Mosimann, U.P., Burn, D.J. et al. (2005), 'Change in perfusion, hallucinations and fluctuations in consciousness in dementia with Lewy bodies', Psychiatry Res. Vol. 139, pp. 79-88.

123. Mori, T., Ikeda, M., Fukuhara, R., Nestor, P.J. et al. (2006), 'Correlation of visual hallucinations with occipital rCBF changes by donepezil in DLB', Neurology Vol. 66, pp. 935-937.

124. Ceravolo, R., Volterrani, D., Frosini, D., Bernardini, S. et al. (2006), 'Brain perfusion effects of cholinesterase inhibitors in Parkinson's disease with dementia', J. Neural Transm. Vol. 113, pp. 1787-1790.

125. Colloby, S. and O'Brien, J. (2004), 'Functional imaging in Parkinson's disease and dementia with Lewy bodies', J. Geriatr. Psychiatry Neurol. Vol. 17, pp. 158-163.

126. Roses, A.D. (2009), 'The medical and economic roles of pipeline pharmacogenetics: Alzheimer's disease as a model of efficacy and HLA-B(*)5701 as a model of safety', Neuropsychopharmacology Vol. 34, pp. 6-17. 